\title{
A Review of hyper mixers to enhance combustion efficiency in supersonic combustor
}

\author{
Antony Athithan Ananthan*, Kalaiarasan Sekar \\ Lecturer, Department of Aeronautics, Faculty of Engineering and Built Environment, Lincoln University College, \\ Malaysia.
}

Correspondence E-mail : antonya@lincoln.edu.my*; kalaiarasan@lincoln.edu.my

\begin{abstract}
Supersonic mixing and combustion enhancement is primarily focused to increase the efficiency of scramjet engine. The research on a fuel injection system performance is widely developing today. In scramjet engine, the air and fuel mixing is improper due to the supersonic flow inside the combustor. The flame instabilization occurs due to less resident time of air which tends to affect the output efficiency and it leads to loss of fuel energy. Hence apart from the modern research studies on various fuel injection techniques inside the supersonic combustor, this study provides the idea of various alternating wedge designs to enhance the air and fuel mixture. Also reducing the consumption of fuel in the combustor gives a great impact in usage of fuel energy efficiently in the aviation field.
\end{abstract}

Keywords: Scramjet, Hyper mixer injector, Alternating wedge injection, Mach number, Combustion efficiency and energy efficient techniques.

\section{Introduction}

Scramjet is a key component for the hypersonic flight operating condition. The scramjet engine is composed of three main components such as converging inlet, combustor and nozzle, as shown in figure 1. In scramjet combustor, the flow should be supersonic. The mixing of air and fuel at supersonic speed in the combustor is the highly challenging process in the supersonic combustor. If the fuel and air mixture is improper, then the flame instabilization will occur in the combustion chamber. Due to the less resident time of air, the hyper mixer fuel injectors or alternative wall injector designs are installed in the combustor to improve the air and fuel mixture.

Hyper mixer injector is a two-dimensional compression ramp at the upstream side and a streamwise vortices generating section. The wedges were formed by extended compression ramp from the upstream side and are arranged alternately in the span width direction (Kubo et al., 2014).

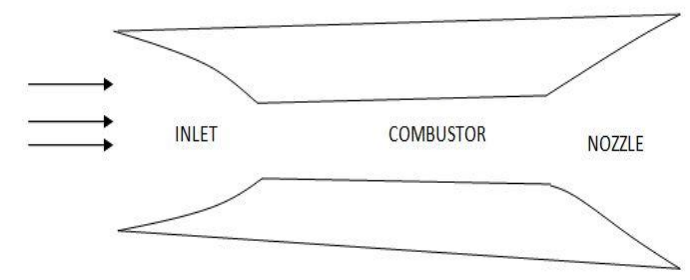

Fig.1: Schematic of Scramjet Engine

Hyper mixer injector is also known as alternating wedge ramp injector. Figure 2 shows the schematic diagram of an alternating wedge hyper mixer. Another type of fuel injector is a strut based fuel injection system. The design of strut mixing device includes both regular and parallel injection method. The 
shock formation at the leading edge of strut improves fuel air mixing. The alternating wedge design at the trailing edge enhances the mixing of air and fuel (Patel et. al., 2015); it is called as alternating wedge strut.

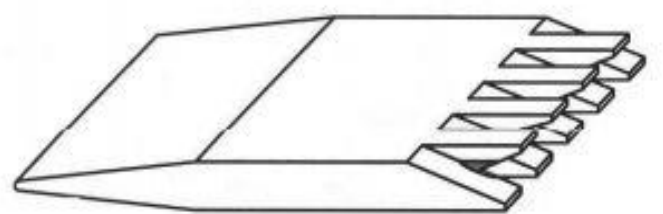

Fig.2: Alternating wedge hyper mixer (Ogawa and Kodera 2015)

\section{Review of Literature}

The combustion efficiency is significantly increased by installing the alternating wedge injection struts, which create longitudinal vortices but reduce the stability of the flame (Fureby et al., 2015). The combustion in alternating wedge injection strut occurs between the sidewalls and a central mixing region, where mixing is facilitated by the vortices and vigorous multimode combustion occurs downstream of the mixing region (Fureby et al., 2015).

The experimental investigation of combustion performance on scramjet engine by applying a swept shape to the ramp wedges of the hyper mixer fuel injectors (Kubo et. al., 2015) shows the higher thrust performance than the nonswept ramp wedges. In the case of wallmounted non-swept ramp injectors, (Kubo et. al., 2015) the combustion performance were significantly decremented. These performance decrements were controlled by using the swept ramp injectors
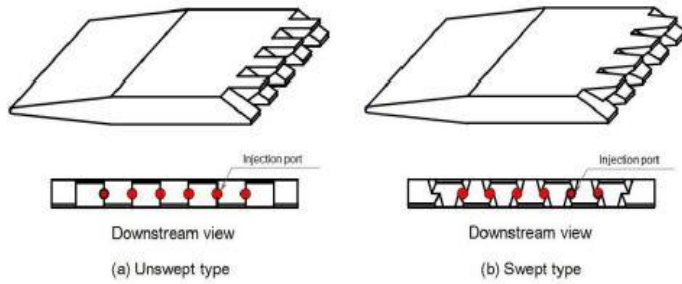

Fig.3: The Schematic of hyper mixer injectors (Strut type) (Kubo et. al., 2015)

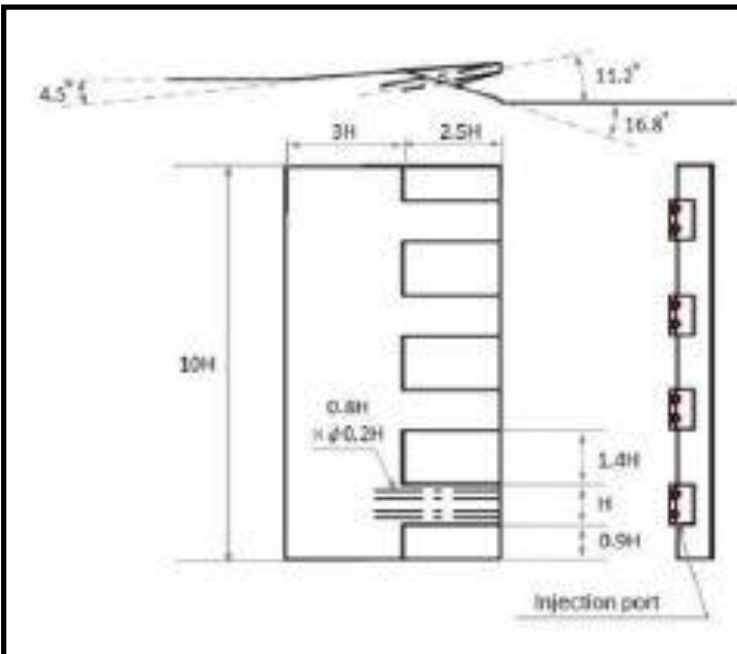

(a) Unswept type

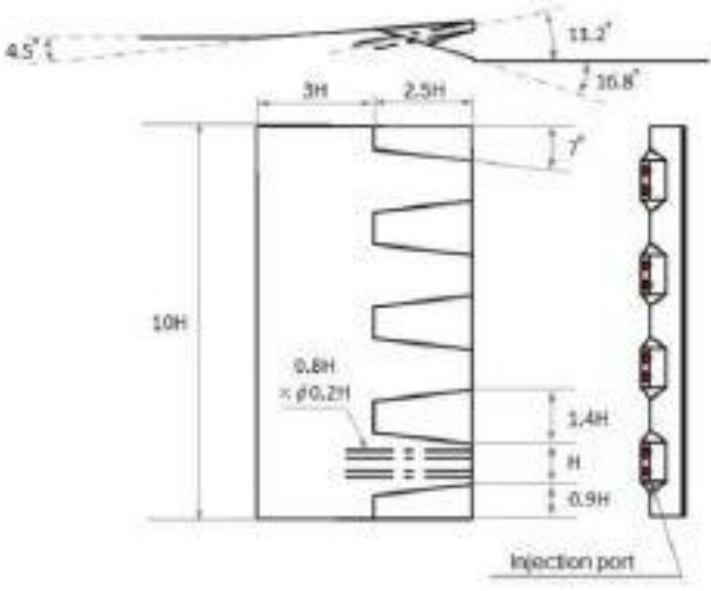

(a) Swept type

Fig.4: The Schematic of hyper mixer injectors (Wall mounted type) (Kubo et. al., 2015)

The numerical study of cavity shaped combustor with backwards-facing step and forward ramp with an injector at a certain inclination angle opposing the inlet flow (Mani et. al., 2015) shows the higher temperature at the exit, which leads to the increase of combustion performance. Also, the higher inclination angle of the injector gives higher efficiency than the injector with a lower angle of inclination. The cavity-based scramjet combustor enhances the fuel/air mixing and improves the flame holding.

The numerical investigation of the hyper mixer with a row of alternating wedges having central fuel injection as shown in fig. 2 (Ogawa 
and Kodera 2015) shows the favorable efficient fuel/air mixing in narrow spanwise spacing which creates strong streamwise vortex but does not improve the fuel/air mixing.

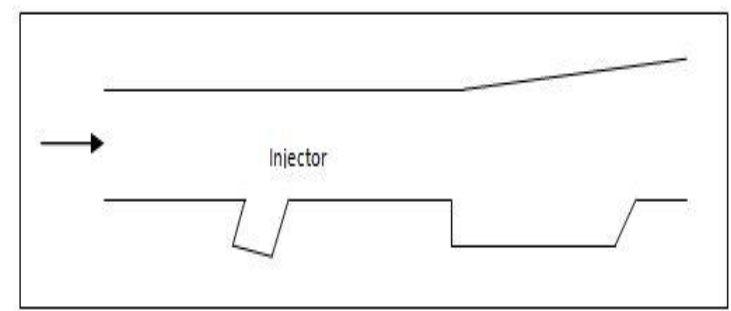

Fig. 5: The Schematic of Cavity shaped combustor

The higher fuel/air mixing is achieved by greater vertical height and augments streamwise vortex circulation with the help of steeper ramp angle (Ogawa and Kodera 2015). The streamwise vortex interaction across the symmetry plans plays a vital role in convective mixing of fuel air.

The numerical investigation of hydrogenfueled scramjet combustor with two types of strut flame holder having circular strut injector, for three angles of attack (Pandey et. al., 2016) shows different performance. For air Mach number 6 in the combustor, the hydrogen is injected to the surrounding flow due to streamwise vorticity created by the circular strut injector, leads to the increase of pressure and temperature which are enough for autoignition. The ignition delay is observed for a different angle of attack. The shortest ignition delay is noted in the negative angle of attack, $\alpha=-4^{0}$, (Pandey et. al., 2016), so the increase of temperature is also observed in the negative angle of attack, whereas the positive angle of attack shows most prolonged ignition delay. For the negative angle of attack, shock trains have been observed, which enhances the combustion and decreases the ignition delay. Thus combustion efficiency is at the maximum level for negative angle of attack (Pandey et. al., 2016).

The numerical analysis has been carried out between double strut and strut side fuel injection models (Obula Reddy et. al., 2017).

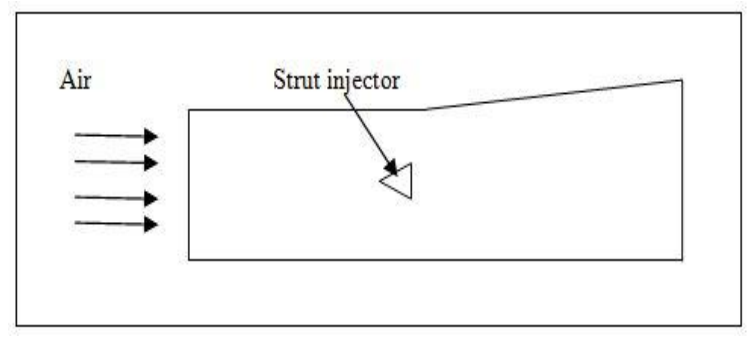

Fig. 6: The Schematic of circular strut injector with Zero angle of attack

The result shows the formation of strong oblique shock at the leading edge of strut and reflected back at combustor internal walls (Obula Reddy et. al., 2017). Due to impinge of strut side fuel jet, more oblique shocks are formed and lead to an increase in static pressure at boundary layer separation. It improves the air and fuel mixing by carrying the fuel jets along with the oblique shocks. Double strut decreases ignition delay (Obula Reddy et. al., 2017). Thus combustion efficiency is higher in strut side fuel injection than double strut model.

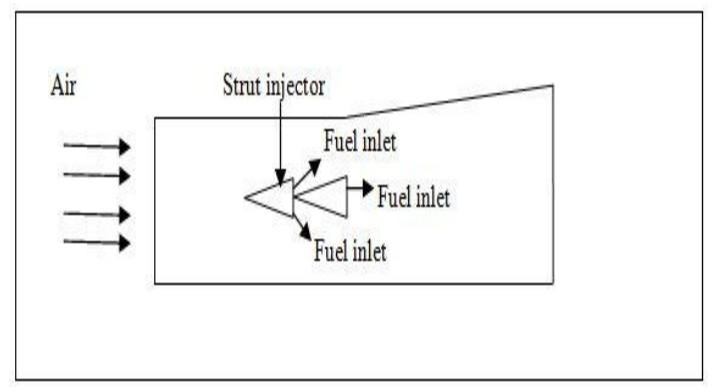

Fig. 7: The Schematic of Scramjet Combustor with strut side (top and bottom) fuel injection and with double strut fuel injection.

The numerical study on flow field characteristics of the different cavity-based scramjet combustors with transverse injection at various angles of injectors (Ambicapathy et al., 2014) shows a variety of flow features resulting from the interactions between injectors flow, boundary layer, cavity flow and shock waves. The overall result shows the cavity shaped combustor with backwardsfacing step and forward ramp with the injector at a $45^{\circ}$ angle of injection which is opposing the inlet flow shows higher temperature compared to other models (Mani et. al., 2015 and Ambicapathy et al., 2014). 


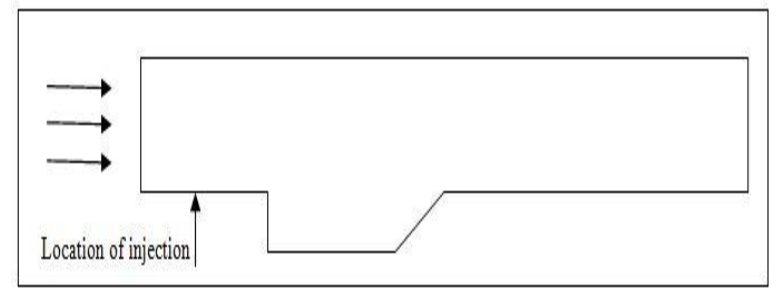

Fig. 8: The schematic of cavity-based scramjet combustor with transverse injector

An experimental study of flush all scramjet combustor model without wall mounting flame holding devices under the stimulated test condition of Mach 6, (Hu et al., 2014), shows the best combustion performance.

\section{Conclusion}

The primary focus in increasing the scramjets performance is determined by increasing the combustor efficiency. Particularly, fuel injection methods are being optimized through various hyper mixers to attain high performance. This study on fuel injector in scramjet combustor shows the enhancement of fuel and air mixture inside the combustor. The alternating wedge injection struts increases the efficiency of the combustion by creating longitudinal vortices. Also by implementing swept ramp injectors, the combustion performance decrements were controlled .The circular strut injector with negative angle of attack shows the maximum level of combustion efficiency when compared with circular strut with positive angle of attack, which is due to decrease of ignition delay and shock train formation in negative angle of attack. The usage of double strut also decreases ignition delay but oblique shock formation is reduced, which carry fuel jets. This study reveals that the combustion efficiency is more in strut side fuel injection than the double strut. Also it was studied that the cavity shaped combustion with an injector having inclination angle creates higher temperature at exit, which in turn provides better performance. The cavity also acts as a flame holder in the combustor. This paper suggest that implementing of cavity shape followed by circular alternating wedge injector with negative angle of attack gives higher performance in fuel and air mixing. Also the flames were stabilized due to the cavity flame holder. These techniques are improved to increase the efficient usage of fuel energy.

\section{Acknowledgement}

We would like to express our deep gratitude to Datuk Ismail Bin Hassan, Former Dean Faculty of Engineering and Built Environment other faculty members of Engineering, Lincoln University College, Malaysia for their enthusiastic encouragement and useful critiques of this research work. We would also like to thank Dr. Mukil Alagirisamy, Deputy Dean of Faculty of Engineering for encourages us to proceed with this work.

\section{Conflict of interest}

The authors declare no conflict of interest.

\section{References:}

Ambicapathy. S., Sivaraj. P, Rakesh. A, Vysaprasad, K., Hemasai. N. D, and Sanal Kumar, V. R. (2014). Diagnostic Investigation of Flow field Characteristics of Cavity based Scramjet Combustors. 50th AIAA/ASME/SAE/ASEE Joint Propulsion Conference. DOI: 10.2514/6.2014-3872.

Fureby, C., Nordin-Bates, K., Petterson, K., Bresson, A. and Sabelnikov, V. (2015). A computational study of supersonic combustion in strut injector and hyper mixer flow fields. Proceedings of the Combustion Institute, 35 (2), p. 2127-2135. DOI: 10.1016/j.proci.2014.06.113.

Hu, J., Chang, J., Bao, W., Yang. Q., and Wen, J., (2014). Experimental study of a flush wall scramjet combustor equipped with strut/wall fuel injection. Acta Astronautica, 104(1):84-90. DOI: 10.1016/j.actaastro.2014.07.012

Kubo, N., Murakamib, A., Kudob, K., and Tomiokaa, S. (2015). An Experimental Investigation on Combustion Characteristics of Hypermixer Injectors --Effects of the 'Swept' Applied to Hypermixer Injector Ramps. Procedia Engineering, 99:954-960. DOI: 10.1016/j.proeng.2014.12.627

Kubo, N., Tomioka, S., Murakami, A., and Kudo, K., (2014). Mixing and Combustion Experiments with Hyper-Mixer Injectors in a Scramjet Combustor. Conference: 50th AIAA/ASME/SAE/ASEE Joint Propulsion Conference. DOI: 10.2514/6.2014-3873.

Mani, S., Ramesh Kumar, T., Ajith. S, Hemasai.N.D, and Sanal Kumar.V.R. (2015). 3D Flow Visualization and Geometry Optimization of Cavity 
based Scramjet Combustors using k- $\omega$ Model. 51st AIAA/SAE/ASEE Joint Propulsion Conference, Project: Complex flow analysis and Optimization. DOI: 10.2514/6.2015-3946

Obula Reddy, K., Suneetha, L., and Pandey, K.M. (2017). Numerical analysis of scramjet combustor with innovative strut and fuel injection techniques. International Journal of Hydrogen Energy, 42(15): 10524-10535. DOI: 10.1016/j.ijhydene.2018.04.067

Ogawa, H., and Kodera, M., (2015). Physical Insight into Fuel/Air Mixing with Hypermixer Injectors for Scramjet Engines. Journal of Propulsion and Power, 31(5):1423-1435. DOI: 10.2514/1.B35638.
Pandey, K.M., Roga, S and Choubey, G. (2016). Numerical Investigation on Hydrogen-Fueled Scramjet Combustor with Parallel Strut Fuel Injector at a Flight Mach Number of 6 . Journal of Applied Fluid Mechanics, 9(3): 1215-1220.

Patel, A., Sahu, G. and Sen, P.K. (2015) A Review on Fuel Injection System of Scramjet Engine. International Journal of Engineering and Management Research, 5 (5): 199-202. 